CALEI-

DOSCOPIO

15

⿶.

ENERO - JUNIO 2004

\title{
EL DOMINIO DE UNA MINORÍA EN EL OCASO DEL SIGLO XVIII
}

GERARDO MARTÍNEZ DELGADO

Departamento de Historia/UAA

Jesús Gómez Serrano, Los españoles en Aguascalientes durante la época colonial. Origen, desarrollo e influencia de una minoría, Zapopan, El Colegio de Jalisco-Fomento Cultural Banamex-Universidad Autónoma de Aguascalientes, 2003, 293 pp.

El autor

La trayectoria de Jesús Gómez dentro del campo de la producción historiográfica se inició formalmente en 1982, cuando en compañía de Enrique Rodríguez Varela publicó Aguascalientes, imperio de los Guggenheim. Detrás de este primer título han seguido muchos más. En sus primeras obras se nota un poco el conflicto que causaba su formación original de sociólogo entreverada con las inquietudes y práctica de la investigación histórica. De hecho, Francisco Javier Delgado considera que varios de sus primeros libros, y en general casi todos los producidos en Aguascalientes durante la década de los ochenta, se pueden describir como propios de una historiografía en ciernes, "...compuesta principalmente por acercamientos monográficos a temas y problemas muy específicos y que en la mayoría de los casos se desarrollan en cortos períodos de tiempo". Además, agrega el mismo Delgado, "...en muchos casos las obras carecen de un argumento o hilo conductor central, pues están compuestas por capítulos 
que no tienen una conexión explícita". ' Es decir, había apenas esbozos de problematización o de uso de teorías generales que plantearan o discutieran procesos o acontecimientos determinados.

Sin duda que la metódica dedicación, tenacidad y dinamismo que ha impreso a su actividad como investigador le han permitido madurar y suplir con creces las carencias que pudo tener por su formación de sociólogo y sus primeros pasos más bien empíricos- como historiador. A lo largo de los años, y eso es muestra clara de nuestra afirmación, ha publicado diecisiete libros, escrito para poco más de veinte obras colectivas, participado en decenas de eventos académicos y recibido premios importantes por su labor historiográfica; pertenece desde hace muchos años al Sistema Nacional de Investigadores, y más recientemente, a la Academia Mexicana de las Ciencias.

Tal como lo demuestra este libro, la obra historiográfica de Gómez Serrano está nutrida de

Francisco Javier Delgado Aguilar, "Por los caminos de la historia regional", en Caleidoscopio, número 8, juliodiciembre de 2000, pp. 193-204. eso que Luis González, con su peculiar y certero estilo, ha llamado "literaturas y vividurías". Me queda claro que sin esas vividurías, a los historiadores nos queda poco que hacer en el mundo de Clío.

\section{Sus intereses historiográficos}

No son pocos los que han encasillado a Jesús Gómez como un historiador de la cuestión agraria, de las haciendas y del siglo XIX. Quien conoce con más detalle su obra, en cambio, sabe de la diversidad de épocas y temáticas a las que ha dedicado serias investigaciones, lo han convertido en el historiador local más prolífico y, como tal, uno de los más respetados en Aguascalientes y reconocidos a nivel nacional.

No debe sorprender, pues, que en el libro que aquí reseñamos se ocupe de la época colonial y de los españoles. La historia, Aguascalientes y lo español son tres de sus grandes pasiones que hoy conforman el triángulo que representa este nuevo texto.

Nacido en Aguascalientes, Jesús Gómez Serrano no podrá ocultar el amor que le tiene al terruño y la pasión que lo ha llevado a interesarse por su 
pasado y por su presente. Hay que decir, sin embargo, que este sentimiento de arraigo está muy lejos de un malentendido provincialismo, pues incluso el conocimiento que ha acumulado sobre la historia de Aguascalientes y la historia en general lo han llevado ha tener un cierto desencanto; no es para menos, de entre las muchas lecturas que pueden hacerse de este libro -sin hacer a un lado desde luego otras más optimistas- quedan grabadas muchas impresiones de la condición humana: ambición, matrimonios por interés, deseos de poder y dominación, conformación de élites segregadoras de amplios grupos sociales, gobernantes que al amparo de sus puestos se dedican a favorecer sus negocios y a dar rienda suelta a sus vicios, etcétera.

Su interés por España y lo español me parece que tampoco es nuevo y, por lo demás, él lo hace explícito en las primeras páginas del libro, cuando rememora sus andanzas por la península.

Este autor se había ocupado ya de estudiar aspectos de la historia colonial en varios de sus libros, entre los que destacan: El mayorazgo Rincón Gallardo,
Hacendados y campesinos en Aguascalientes y en algunos fragmentos de la obra en cuatro tomos Aguascalientes en la historia, 1786-1920.

Ahora bien, ¿por qué elegir a las élites como objeto de estudio? Aunque desde el punto de vista de los intereses del historiador no tiene por qué haber una explicación, pues comprendo perfectamente que a los historiadores nos puede llamar la atención un grupo social en especial, un tema, un período o un campo geográfico de estudio por simple gusto o por razones, a veces de suficiencia documental, o muchas otras no siempre tan claras. La historia de las élites es un excelente mirador de una realidad histórica, no menos que la perspectiva de la historia desde el punto de vista de las clases subalternas, según lo han propuesto y defendido muchos historiadores, entre otros el genial Eric Hobsbawm.

\section{El libro}

El tema principal en el que se inscribe su investigación es el de "la presencia europea en las regiones de México", campo en el que David Brading abrió brecha hace cerca de tres décadas y cuya 
obra ejerce una amplia inspiración y por momentos sirve de modelo a Gómez Serrano.

El objetivo fundamental del libro es "...contribuir al debate sobre la magnitud de la inmigración ibérica en Aguascalientes" y sostiene como tesis central que durante el siglo XVIII la villa reunió un número sobresaliente de españoles, llegando a colocarse como la jurisdicción con más miembros de este origen dentro de la intendencia de Guadalajara, sólo detrás, por supuesto, de la capital de la intendencia, y que estos peninsulares constituían un reducido pero influyente grupo que accedía fácilmente a las posiciones más importantes del gobierno, que poseía algunas buenas haciendas, que sus miembros eran dueños de minas, y sobre todo, que dominaban la actividad económica más importante que se desarrollaba dentro de la villa y su jurisdicción: el comercio.

Hay que aplaudir la virtud del autor, no tan frecuente en los historiadores como debiera ser, de tener una gran penetración y dominio de su tema, lo que le permite estructurar impecablemente su libro, delimitar y titular atinadamente los apar- tados, e indicarnos, resumirnos y anunciarnos con bastante claridad sus propósitos y sus hipótesis que resuelve en el cuerpo de los capítulos.

Una de las primeras teorías secundarias en las que enmarca su investigación es la de las particularidades regionales de los inmigrantes ibéricos. Advierte que a pesar del significativo matrimonio de los Reyes Católicos a finales del siglo XV, "...hasta cierto punto los pueblos españoles siguieron siendo extranjeros entre sí, $[\ldots]$ con sus idiomas y costumbres, sus leyes y administraciones distintas" (p. 28). Esto ayuda sin duda a entender las relaciones que se tejían en la Nueva España, de odio o de solidaridad, condiciones sin las cuales no se explican los éxitos y fracasos de los peninsulares en el nuevo mundo.

Para el caso de Aguascalientes en el siglo XVIII, Gómez Serrano encuentra que hubo un notable predomino de hombres provenientes de la región de Castilla (casi el 60\% del total), pero muy particularmente de las provincias norteñas de Burgos y Santander (42.6\%).

En el segundo capítulo del libro el autor hace un recuento de los primeros peninsulares 
establecidos en la región de Aguascalientes extendiéndose a todo el siglo XVII. Los pioneros debieron ser los descubridores y explotadores de las minas de Zacatecas, Diego de Ibarra y Juan de Tolosa principalmente, quienes por cierto fueron dueños de las minas de Tepezalá.

En este camino, intenta establecer cuál sería la condición racial de los fundadores y primeros pobladores de la villa. Los datos en verdad son escasos, pero tiene razones suficientes para pensar que el carácter de ambos debió ser bastante modesto, atendiendo por ejemplo a la impresión del obispo Mota y Escobar, quien anotó que la villa de Aguascalientes había sido poblada por "gente casi forajida y muy pobre", lo que el autor asimila, con una dosis de pudor, como "...un tono que puede parecer hiriente" (p. 50).

Una de las cosas más importantes que queda asentada en este capítulo es la baja presencia de europeos en la región en todo el transcurso de los siglos XVI y XVII, lo que por una parte refuerza el interés de conocer las condiciones que permitieron que esta situación se revirtiera en la siguiente centuria, pero que también contribuye a comprender mejor las particularidades regionales, pues se manifiesta que la hegemonía peninsular en Nueva España no fue absoluta ni en todos los tiempos ni en todos los lugares como puede llegar a pensarse; más bien, la presencia de los españoles se daba en el momento y en el espacio que les era propicio para figurar, tener poder y aumentar sustancialmente sus caudales.

De estos primeros apartados resultan algunos aportes historiográficos importantes sobre los primeros tiempos de la vida en la villa, contribuciones en las que el mismo Jesús Gómez había participado ya con su reciente libro La guerra chichimeca, la fundación de Aguascalientes y el exterminio de la población aborigen.

Resalta en los capítulos tercero y cuarto la argumentación sobre una pregunta toral en el desarrollo de su teoría principal: ¿qué condiciones se presentaron en la villa -esa que había sido poblada por gente muy pobre y que por años no había llamado la atención particular de nadie- para que un nutrido grupo de españoles se asentaran en ella en el siglo XVIII?

Se encuentran por lo menos tres razones: 1) el auge comercial 
que había alcanzado la región, amparado principalmente por la demanda de productos agrícolas y ganaderos por las minas de Zacatecas, 2) el crecimiento demográfico que se había experimentado, y 3) la importancia que se le concedió a la villa en el proyecto de reorganización militar emprendido a partir de 1780 .

En este punto discute la preeminencia de la villa de Aguascalientes sobre la de Lagos, poniendo en duda lo dicho por Ramón Serrera, quien afirma que esa "vieja rivalidad" se habría resuelto a fines del siglo XVIII a favor de Lagos. Para Gómez Serrano, a mediados del siglo ambas eran "...las más ilustres del reino de Galicia" y juntas constituían -todo según la apreciación de Matías de la Mota Padilla- "...la garganta del comercio de Zacatecas a Guadalajara" (pp. 94-95). Sin embargo, Gómez se inclina a encontrar precisamente en la estratégica ubicación de Aguascalientes, como "...regulador natural de todo el tráfico que iba hacia el norte [una] relativa primacía", lo cual, concluye, es palpable en la comunidad europea que duplicaba en número en ésta a la de Lagos (p. 102).
Ahora, establecida la importancia de la villa de Aguascalientes y la atracción que ejerció sobre los peninsulares, el siguiente paso era seguir la trayectoria de algunos de ellos y explorar sus lugares de origen, los medios o las razones que los hacían llegar a Nueva España y luego a Aguascalientes, y las claves del desempeño que les permitía culminar, en muchos casos, quedando al frente de una pulpería importante u ocupando un cargo en la administración.

Afirma que el sentido de paisanaje fue uno de los elementos básicos: era gracias a esto que los peninsulares establecidos en Nueva España exhortaban y en ocasiones patrocinaban el viaje de sus sobrinos, hijos, hermanos o simples compatriotas para integrarse a sus actividades. Este mismo espíritu ayudaba al recién llegado a involucrarse poco a poco en los negocios de sus protectores y a hacer un buen matrimonio, corolario de su ingreso a la élite regional.

Vale la pena recuperar lo señalado por Alexander Von Humboldt, quien decía que "...el más miserable europeo, sin educación y sin cultivo de su entendimiento, se cree superior a 
los blancos nacidos en el Nuevo Continente" (p. 80). En este sentido, resulta particularmente ilustrativo el caso de Miguel de Arteaga, quien se acogió con su tío Diego de Arteaga "con título de sirviente"; amparado y "tal vez orientado por él", se casó, ni más ni menos, con María Teresa Rincón Gallardo, entenada de don Miguel e hija mayor del entonces difunto Manuel Rincón Gallardo. En 1726 inició un pleito en la Audiencia de Guadalajara, fallando ésta a su favor, de forma que su esposa fue declarada "legítima e inmediata sucesora" de todas las posesiones que integraban el mayorazgo de Ciénega de Mata. Finalmente, y después de un largísimo juicio, el primogénito varón recuperó para sí los bienes vinculados, pero de cualquier manera, dice el autor "...gracias a su oportuno matrimonio, este joven guipuzcoano fue durante algunos años el terrateniente más rico de la región" (pp. 82-84).

El quinto apartado, titulado "Pocos pero influyentes. Los negocios de los inmigrantes", da cuenta del dominio que ejercieron los españoles en el gobierno -como alcaldes mayores y miembros del cabildo-; en los negocios, particularmente en el comercio; como poseedores de tierras; y como integrantes del regimiento de dragones.

Respecto a su participación en el cabildo afirma que "...estuvieron representados con exceso, pues no siendo ni siquiera el uno por ciento de la población, tuvieron en su poder casi la mitad de los cargos..." (p. 120).

En lo que toca al comercio, considera que, "...sin pecar por exageración [...] el comercio regional estuvo por completo en manos de los peninsulares a lo largo de todo el siglo XVIII" (p. 129). En este punto hay dos situaciones encontradas, por un lado, él presenta argumentos sólidos a favor de su tesis: la Junta de Comercio, que era "la asociación de empresarios más influyente que había en Aguascalientes", y a la que sólo tenían acceso los que introducían más de cuatro mil pesos anuales en géneros, "estuvo totalmente controlada por los inmigrantes peninsulares". En 1759, por ejemplo, ocho de sus doce miembros eran peninsulares (pp. 128 136). Pero por otra parte, Beatriz Rojas consigna un dato que no me parece menor en esta discusión y que debilita un poco lo dicho por Gómez: En 1780, el criollo Antonio Vivanco, "rico 
minero de Bolaños", introdujo a través de su administrador el "24\% de la mercancía que entró en Aguascalientes", dejando en segundo lugar al peninsular Juan Francisco Calera, miembro prominente de esa Junta de Comercio, quien a pesar de su conocida posición sólo introdujo poco menos del $7 \%$ del total. ${ }^{2}$

En cambio en el renglón militar no parece haber dudas. En 1800, cuando fue creado el Primer Escuadrón del Regimiento de Dragones Provinciales de la Nueva Galicia, el cuerpo con sede en Aguascalientes contaba con 367 hombres y tenía 48 oficiales; de estos militares con mando, veintiuno eran europeos, pero, dice Gómez Serrano, "...si se observa con más cuidado se verá que esa minoría ocupaba justamente las plazas más importantes y mejor remuneradas [...] entre los oficiales de más baja graduación (sargentos y portaguiones) sólo figuraba un peninsular" (p. 143).

2 Beatriz Rojas, Las instituciones de gobierno y la élite local. Aguascalientes del siglo XVII hasta la independencia, El Colegio de Michoacán-Instituto Mora, México, 1998, pp. 161-162.
Cuando el autor se ocupa de dar seguimiento a un par de familias que fueron fundadas por peninsulares en Aguascalientes, a saber los Emazabel y los Pérez de Terán, destaca la mejor suerte de estos últimos; su fundador, Felipe Pérez Mier y Terán, "un hidalgo pobre" que llegó a Nueva España alrededor de 1750, se estableció en Asientos donde explotó una mina y poco después fue elegido Alcalde Ordinario de la villa. Uno de sus hijos, de su mismo nombre, se encargó de que el apellido siguiera figurando: fue recaudador de diezmos en la jurisdicción, compró algunas buenas tierras, se interesó en los asuntos públicos y alcanzó sus mejores momentos al estallido del movimiento de independencia, cuando fue nombrado comandante militar y subdelegado del partido por Félix Calleja, "con lo que de un solo golpe se convirtió en el funcionario más poderoso de toda la jurisdicción". En esta posición fue muy controvertido, pues cometió excesos contra los insurgentes, a pesar de que sobrevivió sin mayores sobresaltos a la consumación de la independencia. Uno de sus hijos, esto es, la tercera generación, "...figuró a partir de los años veinte como un honrado hombre 
de negocios y un fiel partidario del nuevo orden de cosas" (pp. 162177). La cuarta generación tuvo como protagonista a Jesús Terán, hijo de Jacinto, y -agregaría yotodavía en la sexta, aunque se perdió el apellido, figuró Arturo Pani Arteaga, quien vivió en Aguascalientes los primeros veintitrés años de su vida, y posteriormente nos heredó atractivos testimonios del Aguascalientes porfiriano que le tocó vivir y algunos interesantes datos biográficos de sus familiares, entre los que tuvieron un lugar su tío abuelo Jesús Terán y su tío tatarabuelo, el implacable Felipe Pérez de Terán. Lo sobresaliente en este caso es la apreciación de Jesús Gómez:

De una misma cantera o familia salieron los protagonistas de la contrainsurgencia, los encargados de erigir las nuevas instituciones exigidas por el orden republicano y los defensores de la patria liberal amenazada por los conservadores y sus aliados extranjeros. Detrás de diferentes máscaras, los hombres de los negocios y el poder eran lyo agregaría: son] siempre los mismos. Dicho de otra manera, lo que nos permite observar la historia regional es la permanencia o continuidad de una familia, esa suerte de "gatopardismo" que le permitió a un linaje adaptarse a circunstancias muy diversas y encontrar siempre la forma de mantener a flote sus privilegios ( $\mathrm{p}$. 175).

Una norma que imperaba durante la época colonial era que los hombres de todas las clases, pero particularmente los más favorecidos económicamente, debían contribuir generosamente con la iglesia. "Ilustrar la forma en que esta regla fue respetada por los europeos que se establecieron en Aguascalientes", es lo que da la pauta del séptimo capítulo. El método, en este caso, consiste en elegir tres casos que son bastante representativos de la piedad de estos individuos, aunque no deja de señalar ocasiones excepcionales en las que más de algún personaje favorecido en sus negocios se mostraba avaro con Dios al dictar su testamento. Peculiar y muy publicitada últimamente -que no bien conocida- fue la munificencia de Francisco de Rivero y Gutiérrez, quien con una "piedad ilustrada" y con la acostumbrada disciplina que imprimía a sus negocios concibió y patrocinó con esmero y con visión de largo plazo la primer escuela pública de primeras letras en Aguascalientes, ordenando que en ella se admitieran a todos los muchachos de la villa, "...sin 
excepción alguna de ricos o pobres" (p. 196).

El octavo capítulo se refiere exclusivamente al caso peculiar del andaluz Jacinto López Pimentel. Se da un repaso por sus orígenes, su establecimiento en la villa, su matrimonio ventajoso, sus negocios, su función de recaudador de alcabalas, su incursión en la manufactura textil, su participación en puestos públicos, y su formidable astucia para sortear con éxito toda clase de tempestades. El movimiento de independencia, lejos de sorprenderlo y hacerlo huir, fue uno de los mejores incentivos que tuvo para hacer negocios: su fábrica de paños a la que llamó El Obraje surtió de vestuario a las tropas realistas. "Una vez más se puso de manifiesto la sagacidad del andaluz, que convirtió la guerra que destruía al país en la razón de ser de su nuevo negocio" (p. 227).

Finalmente, la guerra iniciada en 1810 trastocó todos los mecanismos que hasta entonces habían permitido preservar a los peninsulares como un núcleo sólido de la élite local: "Cesó casi por completo el arribo de jóvenes cajeros, que a lo largo de varias generaciones había asegurado la continuidad de esta élite" (p. 240).
El libro en el contexto de la historiografía sobre el tema

En esta obra encuentro por lo menos dos antecedentes muy claros: uno en la historiografía nacional y otro en la local. Respecto al primero, y como lo hicimos notar atrás, se trata del clásico de David A. Brading, Mineros y comerciantes en el México borbónico (1763-1810), en el cual se afirma que durante el siglo XVIII, y especialmente en su parte final, cuando se emprendieron las diversas acciones conocidas genéricamente como reformas borbónicas, "...una inmigración numerosa invadió el continente. Muchos llegaron para ocupar los puestos recién creados en el gobierno y en el ejército, pero la gran mayoría se dedicó al comercio para aprovechar la gran expansión económica de aquellos años". ${ }^{3}$

El propio historiador británico expuso a detalle en esta obra y en otros textos algunas de las teorías que ahora retoma Gómez

${ }^{3}$ David A. Brading, Mineros y comerciantes en el México borbónico (1763-1810), Fondo de Cultura Económica, México, 1997, p. 53. 
Serrano y que analiza a la luz de las peculiaridades de su región de interés; así, y entre otras cosas, Brading había anticipado un retrato de la forma en que se tejían las relaciones en el comercio novohispano: desde la llegada de jóvenes -casi siempre pobres y con poca educaciónllamados y protegidos por un tío o un paisano ya establecido, hasta la manera en que iban ascendiendo posiciones, primero en las rudas y monótonas actividades tras el mostrador y, poco a poco, conociendo los secretos del negocio y preparándose para conquistar a alguna criolla rica, a veces incluso con parentesco. En Mineros y comerciantes, Brading examinó con detalle el censo militar que se levantó en 1792 para la ciudad de Guanajuato, lo que nuestro autor hace ahora para el caso de Aguascalientes .

En el ámbito de la historiografía local, poco abundante aún en lo que al período colonial se refiere, Beatriz Rojas abonó hace un lustro un libro con sustanciales aportes al conoci-miento de nuestro pasado -también influenciado notoria-mente por Brading- en el que adelantó información que hoy retoma bajo otras motivaciones Gómez Serrano. ${ }^{4}$

Todos estos antecedentes, algunos de ellos directamente relacionados con su objeto de estudio, son reinterpretados y analizados bajo la teoría principal del autor, como se ha dicho, la influencia de la minoría europea en Aguascalientes durante los años inmediatos atrás del movi miento de independencia.

Nuevas vertientes de investigación

Como todo buen libro, éste deja a los lectores muchas dudas y plantea nuevas problemáticas que hay que estudiar. Así, me parece que ahora que tenemos un nuevo acercamiento a la sociedad colonial de Aguascalientes, éste se concentra primordialmente en el siglo XVIII, lo que apunta la necesidad de una nueva investigación -en la que sabemos de antemano que nc se va a encontrar dominando a los peninsulares- que profun. dice en ese todavía pocc conocido siglo XVII.

Beatriz Rojas, op. cit. 
Pero quiero referirme más puntualmente a otro asunto del que me quedan muchas interrogantes: el movimiento de independencia. Hace ya tiempo que surgió el debate para explicar las razones por las que en Aguascalientes el movimiento revolucionario de 1910 no presenta ningún alzamiento espectacular, pero hasta ahora me parecen todavía tibios los acercamientos para entender la eclosión de un siglo antes. El propio Jesús Gómez esboza algo en este y otros de sus trabajos; Beatriz Rojas ha hecho lo propio en su texto ya citado y, también recientemente, desde una perspectiva más general, menos cerca de la información menuda, Víctor González ha sugerido una teoría que define a la independencia como un movimiento más bien agrario, lo que habría convertido a varias ciudades en "islas en la tormenta", agregando que Aguascalientes, como subdelegación, era primordialmente urbano. ${ }^{5}$

Víctor Manuel González Esparza. Espacio regional y estado-nación, ICACIEMA-UAA, México, 1999, pp. 119 141.
Sé que el asunto rebasaba los objetivos del libro, pero me atrevo a sugerir que el autor pudo aventurar mayores interpretaciones en base a sus resultados, es decir, ¿no se podría pensar y explorar -siguiendo la historiografía nacional que el abrumador dominio de los peninsulares en los cargos públicos y en las posiciones de control económico fue un factor que prendió en los criollos afanes de cambiar la situación? ¿Cómo explicar el motín de octubre de 1810 en Aguascalientes en busca de españoles? Y dentro de esto, ¿qué papel pudieron jugar los sacerdotes -¿criollos?- exaltando a los indios que iban prestos por lo atractivo que se presentaba el saqueo de bienes? Y en fin, el estudio que hace de los peninsulares y de la sociedad local en la etapa inmediata al estallido del movimiento, ¿qué indicios puede revelar para explicar ese aparente aislamiento de Aguascalientes?

\section{Observaciones adicionales}

Finalmente, es preciso hacer algunas referencias a las fuentes que el autor consultó para la confección de su obra. En primer lugar destaca el análisis 
bibliográfico que incluye alrededor de ciento cincuenta títulos - incluidos los artículos de revistas especializadas-; en lo tocante a la consulta documental, destaca el provecho que sacó del archivo colonial de la familia Rincón Gallardo, gracias al cual reconstruyó pasajes importantes de la vida de por lo menos un par de peninsulares, lo que por cierto abona también a lo ya dicho antes por él en sus libros dedicados al mayorazgo de Ciénega de Mata.

El aprovechamiento que hizo del censo militar que levantó Calleja en 1792 en la jurisdicción de Aguascalientes, localizado en el Archivo General de la Nación, fue básico para sustentar su teoría principal; este documento ha sido revisado y citado muchas veces, pero generalmente sólo en lo que corresponde a la descripción de la villa; Gómez Serrano hizo una revisión mucho más minuciosa que aporta información hasta ahora no considerada. Hubo búsquedas también en el Archivo General de Indias, en los archivos parroquial, municipal y del estado de Aguascalientes, a más de algunos otros en Guadalajara y Zacatecas.

En cuestiones de forma hay que decir que el libro fue detalladamente revisado y cuidadosamente impreso. Está conformado por 293 páginas numeradas, incluido un apéndice con el catálogo de "Españoles peninsulares y otros extranjeros radicados en Aguascalientes durante el siglo XVIII", valioso instrumento de consulta en el que se presentan pequeñas semblanzas de los 216 inmigrantes que el autor registró.

Figuran también en la parte final de la obra, tres mapas, dos de España y uno de la alcaldía mayor de Aguascalientes, todos del siglo XVIII. Estos mapas son sin duda muy útiles como referentes para el lector poco familiarizado con la conformación regional y provincial española, e incluso con la de Aguascalientes. Sin embargo, su colocación me sugiere más bien un "relleno" y no una herramienta para los lectores. En este sentido, el libro pudo ser mucho más generoso en imágenes y mapas, elementos que siempre contribuyen al mejor entendimiento de lo expuesto.

\section{Comentarios finales}

La literatura histórica en Aguascalientes se había ocupado ya indirectamente de los peninsulares en todo este período, e incluso había señalado 
la influencia de este grupo en la sociedad aguascalentense del siglo XVIII. Sin embargo, y en eso radica el principal mérito de este libro, para Jesús Gómez el asunto no deriva de otra cosa, sino que es su interés principal; el hilo conductor de su libro se ocupa de profundizar, entender y explicar los orígenes, el número, la importancia y las coincidencias y particularidades de la presencia de este grupo y su paso por Aguascalientes en el marco general de la Nueva España.

No me queda más que saludar la aparición de este nuevo libro, que de entrada supera con creces las expectativas de su autor, quien anotó en la introducción: "...espero que mi libro pueda ser leído $[\ldots]$ como un intento de conocer y comprender mejor la historia de Aguascalientes en la época colonial" (p. 24). Además de lograr esto, me parece todavía más importante señalar que esta obra contribuye a abrir nuevas discusiones que nos permitirán plantear y en su caso resolver problemas historiográficos y, en última instancia, nos alumbrarán para el mejor entendimiento de nuestro pasado y una comprensión más cabal de nuestro presente. 